\title{
APPLICATION OF ARTIFICIAL BEE COLONY ALGORITHM AND FINITE ELEMENT ANALYSIS FOR OPTIMUM DESIGN OF BRUSHLESS PERMANENT MAGNET MOTOR
}

\author{
R. ILKA ${ }^{1}$, S. ASGHAR GHOLAMAIN ${ }^{1}$, H.A. KHOLERDI ${ }^{1}$ \\ AND A. EBRAHIMZADEH ${ }^{1}$ \\ 1Department of Electrical and Computer Engineering, \\ Babol University of Technology, Babol, Iran.
}

ilka@stu.nit.ac.ir; gholamian@nit.ac.ir; h.kholerdi@stu.nit.ac.ir; e_zade@nit.ac.ir

\begin{abstract}
This paper develops a mathematical relationship for the purpose of designing and selecting the optimum dimensions of a brushless permanent magnet motor. The design is optimised by the use of artificial bee colony algorithm with the goal of maximizing the power density and efficiency of the motor. The required dimensions of the brushless motor are calculated based on the optimum power density and efficiency requirements. Finally, the predicted results of the optimisation are validated using a 2-D numerical program based on finite element analysis.
\end{abstract}

ABSTRAK: Kajian ini mencadangkan persamaan yang menghubungkan rekabentuk dan dimensi magnet motor kekal tanpa berus. Rekabentuk optima berdasarkan algorisma koloni lebah tiruan dengan tujuan meningkatkan ketumpatan kuasa dan keberkesanan dibentangkan dalam kajian ini. Dimensi magnet motor kekal tanpa berus dihitung dengan ketumpatan kuasa optima dan keberkesanan. Akhirnya, keputusan telah disahkan dengan menggunakan program berangka 2-D berdasarkan analisis elemen finit.

KEYWORDS: brushless; permanent magnet motor; power density; artificial bee colony; algorithm; finite element analysis

\section{INTRODUCTION}

A brushless permanent magnet (PM) motor has the highest performance in terms of power density and efficiency among different types of electrical motors. Brushless PM motors are widely used as drives of blowers and fans which are highly applicable in telecommunications, electronics, and industrial equipment applications [1-3]. Brushless DC motors are similar to AC synchronous motors. The major difference is that synchronous motors develop a sinusoidal back EMF in comparison to a rectangular, or trapezoidal, back EMF of brushless DC motors. The stator of both types of motors has rotating magnetic fields that produce torque in rotor [2-5]. The stator windings are like a poly phase AC motor, and the rotor has some permanent magnets [3].

Design of brushless PM motors with high power density is an important issue which has attracted researchers' attention [3-7]. In this paper, a novel technique for design of a brushless permanent magnet motor is proposed in which a combination of power density and efficiency is optimized. For this purpose, artificial bee colony algorithm, a recent optimization method, is applied. The rest of the paper is organized as follow: section-2 explains design equations. Section-3 presents the artificial bee colony algorithm. Section- 4 demonstrates optimization results and in section-5 simulation results of finite element analysis are presented. Finally, the paper is concluded in section- 6 . 


\section{DESIGN EQUATIONS}

\subsection{Parameter description}

Figure 1 shows the structure of a typical three-phase brushless dc motor. Table 1 describes the parameters of motor [3-5]. In the design equations that follow, the approach is to start with basic motor geometrical constraints and a magnetic circuit describing magnet flux flow. The considered radial flux topology is shown in Fig. 2. Figure 3 shows slot geometry for the radial flux motor topology [2].

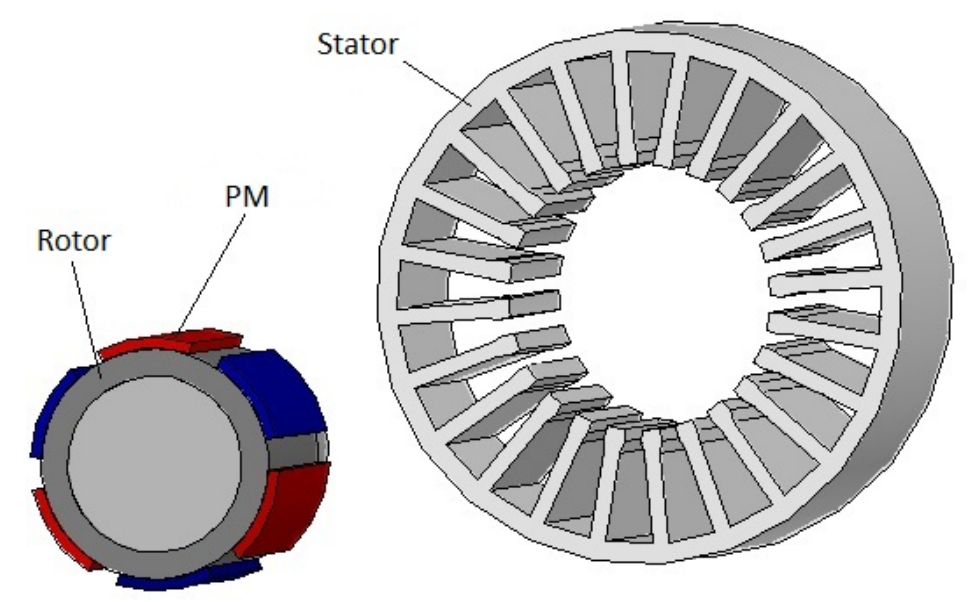

Fig. 1 Disassembled view of a brushless dc motor.

Table 1: Parameter description.

\begin{tabular}{|l|l|l|}
\hline Symbol & Parameter Description & Unit \\
\hline $\mathrm{P}$ & Power & $\mathrm{Hp}$ \\
\hline $\mathrm{T}$ & Rated torque & $\mathrm{N} . \mathrm{m}$ \\
\hline $\mathrm{S}_{\mathrm{r}}$ & Rated speed & $\mathrm{rpm}$ \\
\hline $\mathrm{E}_{\mathrm{max}}$ & Maximum counter-emf & $\mathrm{V}$ \\
\hline $\mathrm{J}_{\max }$ & Maximum slot current density & $\mathrm{A} / \mathrm{m} 2$ \\
\hline $\mathrm{N}_{\mathrm{ph}}$ & Number of phases & \\
\hline $\mathrm{N}_{\mathrm{m}}$ & Number of magnet poles & \\
\hline $\mathrm{g}$ & Air gap length & $\mathrm{m}$ \\
\hline $\mathrm{L}_{\mathrm{pm}}$ & Magnet length & $\mathrm{m}$ \\
\hline $\mathrm{R}_{\mathrm{so}}$ & Outside stator radius & $\mathrm{m}$ \\
\hline $\mathrm{R}_{\mathrm{ro}}$ & Outside rotor radius & $\mathrm{m}$ \\
\hline $\mathrm{R}_{\mathrm{si}}$ & Inside stator radius & $\mathrm{m}$ \\
\hline $\mathrm{R}_{\mathrm{ri}}$ & Inside rotor radius & $\mathrm{m}$ \\
\hline $\mathrm{R}_{\mathrm{sb}}$ & Bottom slot radius & $\mathrm{m}$ \\
\hline $\mathrm{L}_{\mathrm{n}}$ & Motor axial length & $\mathrm{m}$ \\
\hline $\mathrm{K}_{\mathrm{st}}$ & Lamination-stacking factor & \\
\hline $\mathrm{K}_{\mathrm{cp}}$ & Conductor-packing factor & \\
\hline $\mathrm{B}_{\mathrm{r}}$ & Magnet remanence & $\mathrm{T}$ \\
\hline$\mu_{\mathrm{r}}$ & Magnet recoil permeability & \\
\hline $\mathrm{B}_{\mathrm{max}}$ & Maximum steel flux density & $\mathrm{T}$ \\
\hline
\end{tabular}




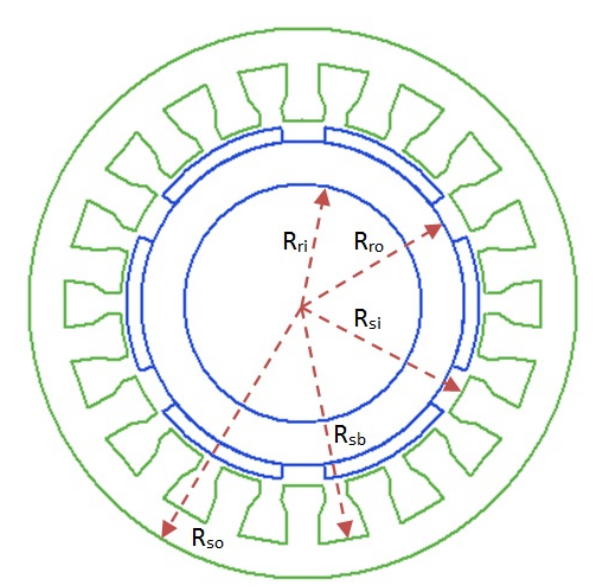

Fig. 2 Motor topology showing geometrical definitions.

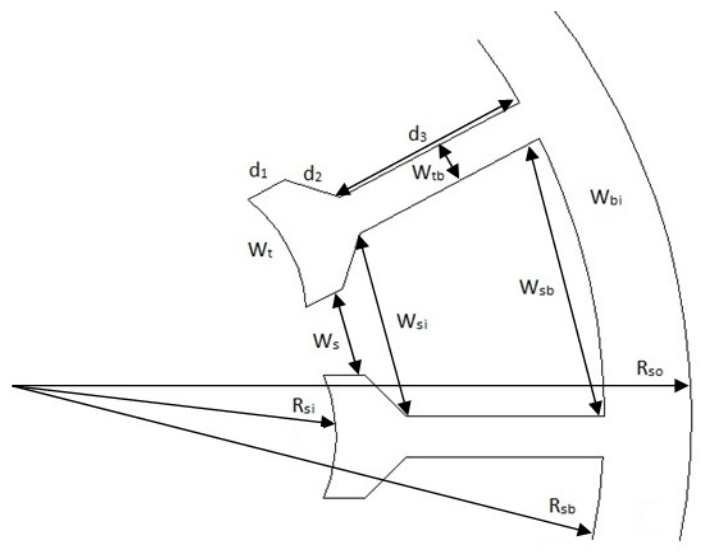

Fig. 3 Slot geometry for motor topology.

\subsection{Geometric Parameters}

Having the parameters shown in Fig. 2 and Fig. 3, it is possible to identify important geometric parameters. The various radii are associated by [2]

$$
\begin{aligned}
& R_{s b}=R_{s o}-\omega_{s y} \\
& R_{s i}=R_{s b}-d_{s}=R_{r o}+g \\
& R_{r i}=R_{r o}-L_{p m}-\omega_{r y}
\end{aligned}
$$

The pole pitch at the inside surface of the stator is related to the angular pole pitch by

$$
\tau_{p}=R_{s i} \theta_{p}
$$

Where, $\theta_{p}=\frac{2 \pi}{N_{m}}$ is the angular pole pitch in mechanical radians, and the coil pitch at the rotor inside radius is,

$$
\tau_{c}=\alpha_{c p} \tau_{p}
$$

Where, $\alpha_{c p}$ is given by Eq. (4):

$$
\alpha_{c p}=\frac{\operatorname{int}\left(N_{s p p}\right)}{N_{s p p}}
$$


$N_{s p p}$ is Number of slots per pole per phase. The slot pitch at the rotor inside radius is

$\tau_{s}=R_{s i} \theta_{s}$

Where, $\theta_{S}=\frac{2 \pi}{N}$

And $\theta_{s}$, is the angular slot pitch in mechanical radians. Knowledge of the slot opening gives the tooth width at the stator surface of

$\omega_{t}=\tau_{s}-\omega_{s}$

The width of the slot bottom is given by

$\omega_{s b}=R_{s b} \theta_{s}-\omega_{t b}$

Given that $d_{s}=d_{1}+d_{2}+d_{3}$ and

$d_{1}+d_{2}=\omega_{t b} \cdot \alpha_{s d}$

The conductor slot depth is $d_{3}=d_{s}-\alpha_{s d} \cdot \omega_{t b}$. In addition, the slot width just beyond the shoes is,

$$
\omega_{s i}=\left(R_{s i}+\alpha_{s d} \omega_{t b}\right) \theta_{s}-\omega_{t b}
$$

As shown in Fig. 3, the stator teeth have parallel sides while the slots do not. However, the situation where the slots have parallel sides and the teeth do not is equally valid. A trapezoidal-shaped slot area maximizes the winding area available and is commonly implemented when the windings are wound randomly, i.e., they are wound turn by turn without any predetermined orientation in a slot [2]. On the other hand, a parallel-sided slot with no shoes is more commonly used when the windings are fully formed prior to insertion into a slot. The unknowns in the preceding equations are the back-iron widths of the rotor and stator $\omega_{b i}$. Given these two dimensions, all other dimensions can be found. In particular, the total slot depth is given by

$$
d_{s}=R_{s b}-R_{\text {ro }}-g
$$

\subsection{Magnetic Parameters}

The flux from each magnet splits equally in both the stator and rotor back irons and is coupled to the adjacent magnets. Thus, the back iron must support one-half of the air gap flux; that is, the back-iron flux is,

$$
\varphi_{b i}=\frac{\varphi_{g}}{2}
$$

If the flux density allowed in the back iron is $B_{\max }$ om the table of fixed values, then the preceding equation dictates that the back-iron width must be,

$$
\varphi_{b i}=\frac{\varphi_{g}}{2 B_{\max } K_{s t} L}
$$

Where, $K_{s t}$ is the lamination-stacking factor.

Since there are $N_{s m}=\frac{N_{s p p}}{N_{p h}}$ slots and teeth per magnet pole, the air gap flux from each magnet travels through $N_{s m}$ teeth. Therefore, each tooth must carry $\frac{1}{N_{s m}}$ of the air gap flux. If the flux density allowed in the teeth is also $B_{\max }$ he required tooth width is,

$$
\omega_{t b}=\left(\frac{2}{N_{s m}}\right) \omega_{b i}
$$


Using Eq. (12) and Eq. (13), all geometric parameters are obtained.

The PM length ( $\left.\mathrm{L}_{\mathrm{PM}}\right)$ can be calculated as

$$
L_{P M}=\left(\frac{\mu_{r} B_{g}}{B_{r}-\left(\frac{K_{f}}{K_{d}}\right) B_{g}}\right) K_{c} g
$$

where, $\mu_{r}$ is the recoil relative permeability of the magnet, $B_{r}$ is the residual flux density of the PM material, $K_{d}$ is the leakage flux factor, $K_{c}$ is the Carter factor, $K_{f}=\frac{B_{g p k}}{B_{g}}$ is the peak value corrected factor of air gap flux density in radial direction of the motor. These factors can be obtained using FEM analysis [6-8].

\subsection{Electrical Parameter}

To find the electrical parameters, it is necessary to specify the relationship between torque and the other motor parameters. The torque developed by a single phase when $N_{s p p}=1$ is,

$$
T=2 N_{p h} B_{g} L I R_{r o}
$$

where the product in parentheses is the force produced by the interaction of $N_{m}$ magnet poles providing air gap flux density $\left(B_{g}\right)$, with each pole interacting with ns conductors each carrying a current $i$ exposed to $B_{g}$ over a length $L$. In this situation, where there may be more than one slot per pole per phase, ns must be replaced by the number of turns per pole per phase $n_{t p p}=N_{s p p n s}$, which gives a torque expression of,

$$
T=N_{m} B_{g} L I R_{r o} N_{s p p} n_{s}
$$

If $N_{s p p}>1$, the air gap flux density must be modified by the distribution factor and pitch factor. Moreover, if the magnets are skewed, the skew factor given in Eq. (17) must be included.

$$
K_{s}=1-\theta_{s e} / 2 \pi
$$

Inclusion of these terms gives a final torque expression of,

$$
T=N_{m} K_{w} K_{s} B_{g} L I R_{r o} N_{s p p} n_{s}
$$

Now, using Eq. (18) and the input-output power relationship T. $\omega=e_{b} . i$, the peak counter-emf at rated speed $\omega_{m}$ is,

$$
E_{\text {max }}=T \cdot \frac{\omega_{m}}{I}=2 N_{p h} B_{g} L \omega_{m} R_{r o} K_{p} K_{d} K_{s}
$$

\section{ARTIFICIAL BEE COLONY ALGORITHM}

Artificial Bee Colony $(\mathrm{ABC})$ algorithm is a swarm-based algorithm. ABC, proposed by Karaboga in 2005, is inspired from the foraging behavior of bee colony. Main applications of the algorithm are solving continuous optimization problems and optimizing multivariable and multi-modal numerical functions. Using fewer control parameters than other algorithms, ABC has better performance.

A colony of honey bees start foraging by sending scout bees to perform a random search for promising food sources. The colony has the ability to explore long distances (about $14 \mathrm{~km}$ ) in multiple directions which assures exploiting a large number of patches $[9,10]$. As the foraging process advances, a number of bees in colony are always assigned 
as scout bees [10]. If the food gathered from a patch meets a criterion threshold, the scout bee can deposit it in the hive and advertises the relative patch in the waggle dance [9]. The waggle dance is an important means for communication in the colony and provides it with all the necessary information of the outside [9-12]. The bees in the hive to choose among different patches according to the information gained from waggle dances about their relative qualities. Thus more bees visit the more promising patches $[11,12]$, this helps an efficient foraging process. Recruiting more bees to a promising patch continues until the patch fitness is decided to fall below the criterion threshold.

$\mathrm{ABC}$ algorithm is initialized by finding random population from the search space with Eq. (20) i.e. the initial population phase:

$$
x_{m i}=x_{i}^{\min }+\operatorname{rand}\left(x_{i}^{\max }-x_{i}^{\min }\right)
$$

where $x_{m i}$ is a solution vector for optimization problem, $m=1, \ldots, S N$ and $i=1, \ldots, n$. SN denotes number of initial population and each $x_{-} i$ is a $\mathrm{n}$-dimensional vector. Then, the fitness of each solution is calculated.

Next step is the employed bees phase in which a new solution is produced in the neighborhood of $x_{i}$ for each solution.

$$
\begin{aligned}
& v_{m i}=x_{i m}+\varphi_{\mathrm{mi}}\left(\mathrm{x}_{\mathrm{mi}}-\mathrm{x}_{\mathrm{ki}}\right) \\
& k=\operatorname{int}(\text { rand. } S N)+1
\end{aligned}
$$

In Eq. (21), $\varphi_{m i}$ is a monotonic distribution of a real random number between $[-1,1]$. $x_{k i}$ denotes ith dimension of $k^{t h}$ solution of population that $k$ is chosen randomly among $\{1, \ldots, S N\}$. The new solution is replaced with the previous only if it has a better fitness.

In the onlooker bee phase each onlooker bee chooses a solution based on its probability amount calculated with Eq. (23), by using a selection method (e.g. Roulette Wheel). Then, the onlooker bee finds a new solution in the neighborhood of the chosen solution. It is replaced, if it is better than the previous one. The number of onlooker bees is equal to $S N$.

$$
\stackrel{r}{P_{m}}=\frac{f i t_{m}\left(\begin{array}{l}
r \\
x_{m}
\end{array}\right)}{\sum_{m=1}^{S N} f i t_{m}\left({ }_{x_{m}}^{r}\right)}
$$

where, $f i t_{m}\left(\begin{array}{l}r \\ x_{m}\end{array}\right)$ is the fitness of $x_{m}$.

If the number of cycles that a solution cannot be improved is greater than a predetermined value (limit), the solution is discarded and a new one is produced randomly. These phases are repeated until a stopping criterion is satisfied. The flowchart of the proposed method has been shown in Fig. 4.

\section{ABC OPTIMIZATION RESULTS}

In this section, results of $\mathrm{ABC}$ algorithm for optimum design of brushless PM motor are presented. Nominal design parameters of this motor and related restriction are presented in Table 2.

In this work, we use $\mathrm{ABC}$ algorithm to maximize three goal functions in three codes: the output power per volume $\left(F_{1}\right)$, the efficiency of brushless $P M$ motor $\left(F_{2}\right)$, and combination of the two first functions $\left(F=\frac{F_{1}}{\alpha_{1}}+\frac{F_{2}}{\alpha_{2}}\right.$ where $\alpha_{1}$ and $\alpha_{2}$ are respectively the maximum value of $F_{1}$ and $F_{2}$ obtained from optimizing each of them separately). The 
algorithm changes $B_{g}, L, R_{r i}$ and $g$ variables to optimize goal functions. Control parameters are limit, $S N$, and iteration:

- Limit: the number of cycles that a solution is not improved

- $S N$ : the size of initial population, and

- Iteration: the number of repetition until arriving to convergence.

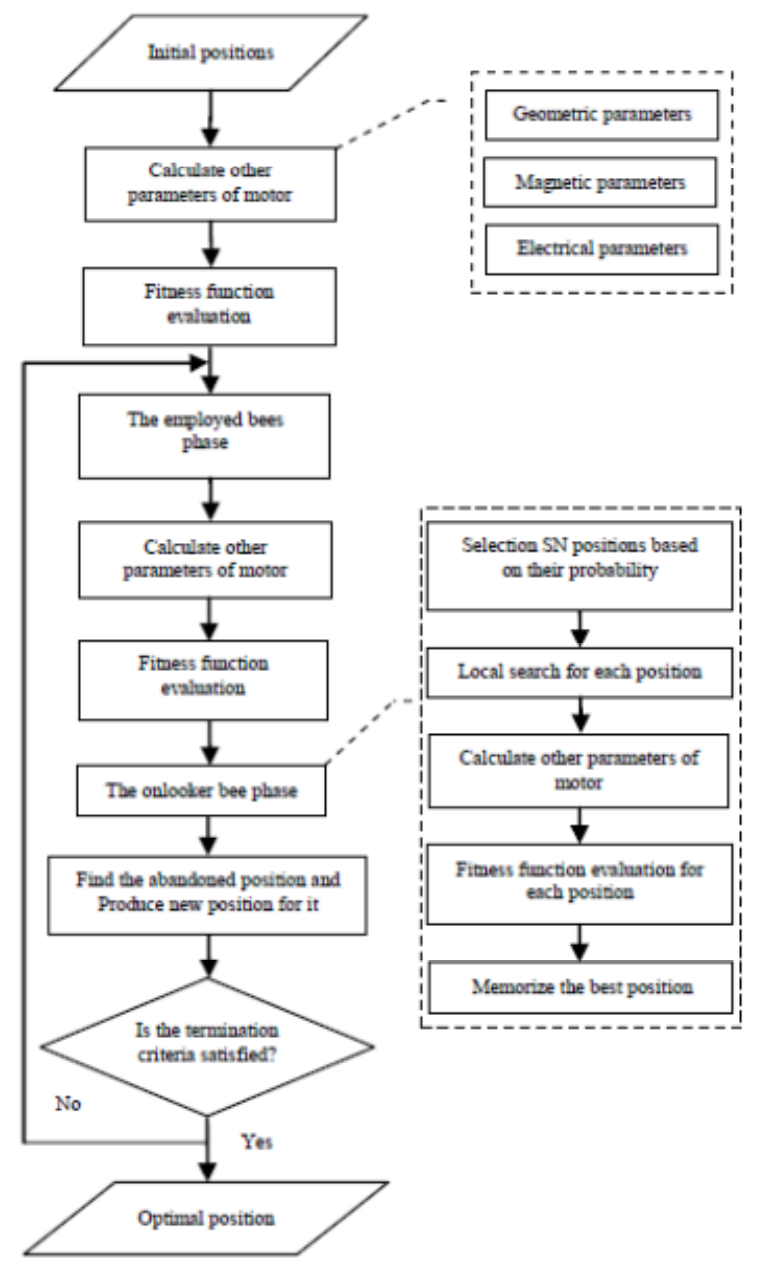

Fig. 4 Flowchart of the proposed method

Table 2: Nominal design parameters of motor.

\begin{tabular}{|l|l|}
\hline Value & Design Parameters \\
\hline $220 \mathrm{~V}$ & Voltage \\
\hline 6 & Number of poles \\
\hline 3 & Number of phases \\
\hline 24 & Number of slots \\
\hline 0.9 & Slot fill factor \\
\hline $1 \mathrm{KW}$ & Output power \\
\hline $1.5 \mathrm{~T}$ & Flux density in stator \\
\hline $1.5 \mathrm{~T}$ & Flux density in rotor \\
\hline $1.1 \mathrm{~T}$ & Residual flux density of PM \\
\hline
\end{tabular}


We changed the parameters several times to obtain best result. Large value of $S N$ slows the speed of convergence but gives the best result. Then $S N$ should be large enough to compromise between best result and the speed of convergence. Limit value should be large enough to control global search while very large value makes the algorithm random. Iteration should be large enough so that convergence is ensured while too large value is redundant. We select $S N=40$, Limit $=10$ and Iteration $=300$.

Figure 5 shows power density unit $\left(F_{1}\right)$ versus iteration. The optimum value of power density is $1.7056(\mathrm{~W} / \mathrm{cm} 3)$. Figure 6 shows efficiency $\left(F_{2}\right)$ versus iteration. The optimum value of efficiency is $92.92 \%$. Fig. 7 shows combination of efficiency and power density $(F)$ versus iteration. The optimum value of goal functions and the amount of variables and output values of PM motor are represented in Table 3.

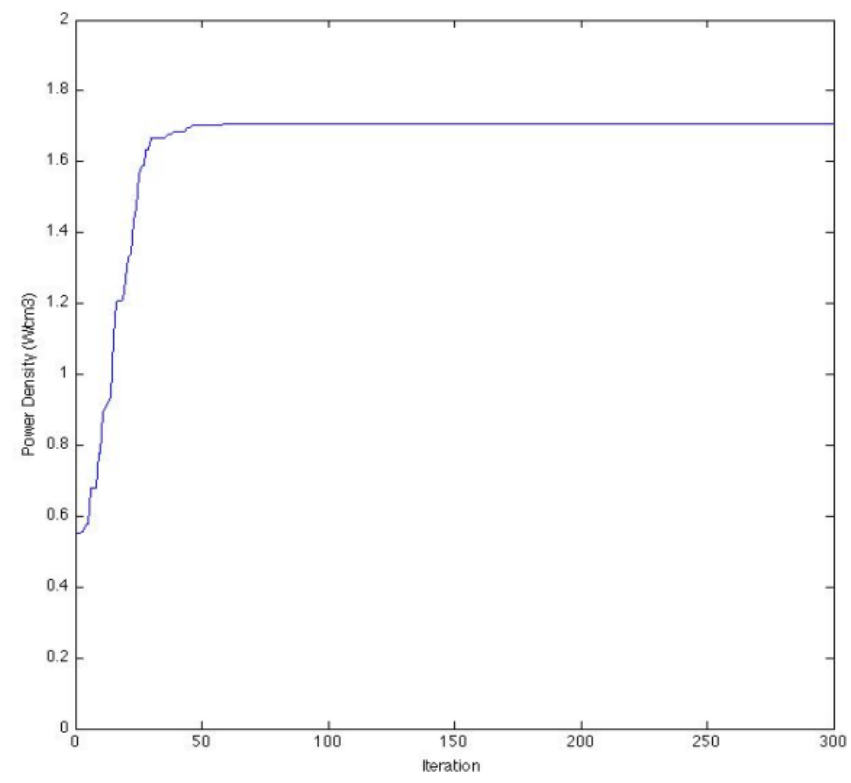

Fig. 5 Power density unit $\left(F_{1}\right)$ versus iteration.

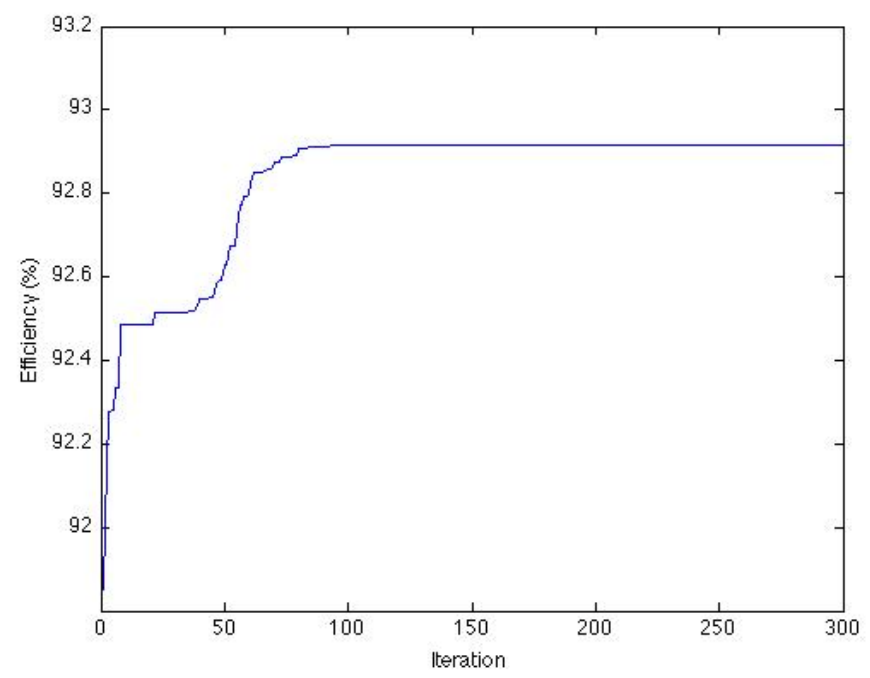

Fig. 6 Efficiency $\left(\mathrm{F}_{2}\right)$ versus iteration. 


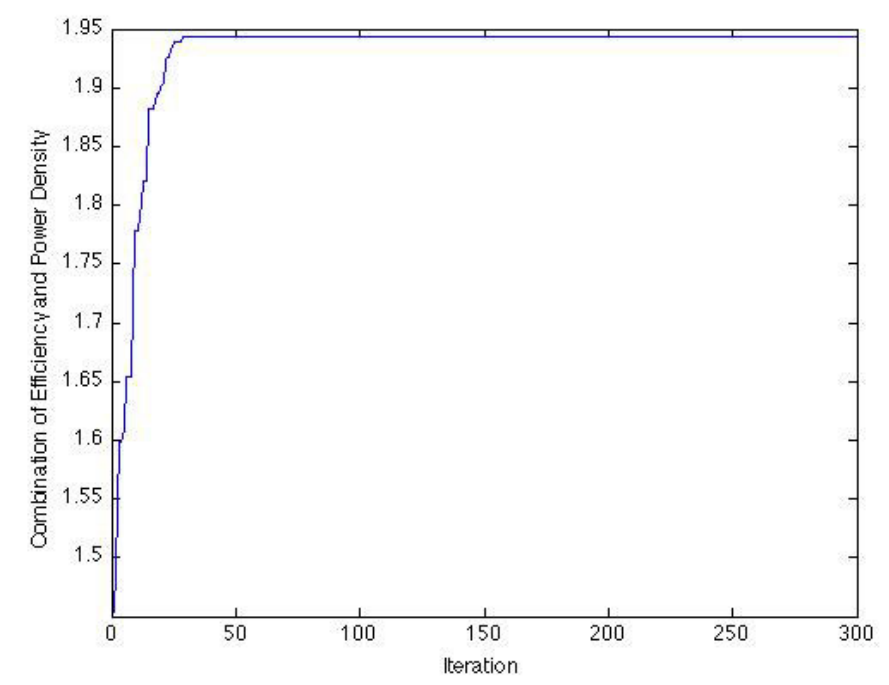

Fig. 7 Combination of efficiency and power density $(F)$ versus iteration.

Table 3: Dimensions of optimal combination of efficiency and power density for brushless $P M$ motor.

\begin{tabular}{|l|l|}
\hline Value & Design Parameters \\
\hline \hline 0.5498 & $\mathrm{Bg}$ \\
\hline $15 \mathrm{~mm}$ & $\mathrm{R}_{\mathrm{ri}}$ \\
\hline $1 \mathrm{~mm}$ & $\mathrm{~g}$ \\
\hline $90.8 \mathrm{~mm}$ & $\mathrm{~L}$ \\
\hline $1.9 \mathrm{~mm}$ & $\mathrm{~L}_{\mathrm{PM}}$ \\
\hline $21.5 \mathrm{~mm}$ & $\mathrm{R}_{\mathrm{ro}}$ \\
\hline 999 & $\mathrm{~N}_{\mathrm{ph}}$ \\
\hline $4.6 \mathrm{~mm}$ & $\mathrm{~W}_{\mathrm{ry}}$ \\
\hline $45.4 \mathrm{~mm}$ & $\mathrm{R}_{\mathrm{so}}$ \\
\hline $18.4 \mathrm{~mm}$ & $\mathrm{~d}_{\mathrm{s}}$ \\
\hline $2.8 \mathrm{~mm}$ & $\mathrm{~W}_{\mathrm{s}}$ \\
\hline $22.5 \mathrm{~mm}$ & $\mathrm{R}_{\mathrm{si}}$ \\
\hline $5.5 \mathrm{~mm}$ & $\mathrm{~W}_{\mathrm{si}}$ \\
\hline $40.8 \mathrm{~mm}$ & $\mathrm{R}_{\mathrm{sb}}$ \\
\hline $1.9 \mathrm{~mm}$ & $\mathrm{~W}_{\mathrm{tb}}$ \\
\hline $1.7056 \mathrm{~W} / \mathrm{cm}^{3}$ & Power density \\
\hline $92.92 \%$ & Efficiency \\
\hline
\end{tabular}

\section{FINITE ELEMENT ANALYSIS}

The finite element analysis (FEA) which found its way into electrical engineering almost 30 years ago, has long offered the tantalizing promise of providing us with a design tool that gives detailed information about the electromagnetic conditions within the heart of a motor. The advantage of numerical methods like the finite element analysis is that arbitrary shapes, arbitrary boundary conditions and complicated or distributed sources, can be used with essentially no extra effort [14]. 
Chari and Silvester [13] were the first authors who used FEA in the analysis of electromagnetic problems, where it was followed by the implementation of FEA in the analysis of DC motors, SR motors and etc. In applying the finite element method, we divide the space of interest into small (but finite) regions called elements, which completely cover the space but does not overlap. Additionally we require that an individual element does not cross a material boundary. We then assume that over this small region, the unknown quantity can be described by a simple function, polynomials are usually chosen because the formulation involves differentiating and integrating these functions. The order of polynomial determines the order of the element. Depending on the geometry of the model, particularly in large motors, only one pole or a smaller fraction of a motor may be modeled [14].

This paper uses Maxwell 2-D software in Magnet-Static mode as FEA analyzer. Optimized dimensions of the motor (Table 3) are implemented in this software. Surfacemounted pole is composed of $\mathrm{NdFe} 30$ with residual flux density of $1.1 \mathrm{~T}$.

Running the software gives preferred output quantities. In this analysis, the total number of mesh elements is 5728. Figure 8 shows the flux lines in the motor. Flux density distribution is shown in Fig. 9. As shown in this figure, maximum flux density occurs in the corners of the tooth as field variations are very fast in these regions.

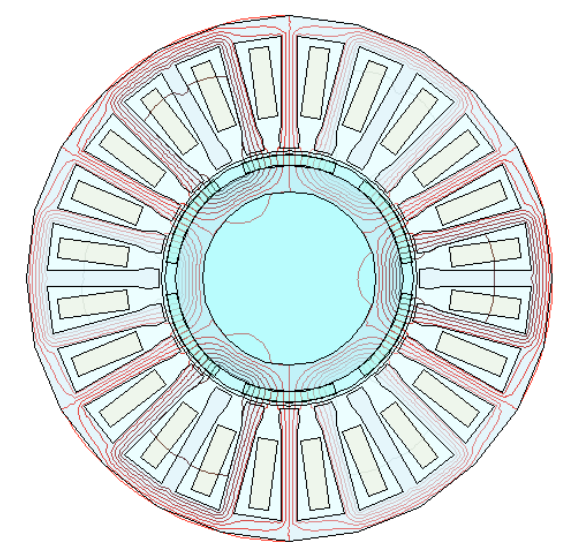

Fig. 8 Flux lines diagram.

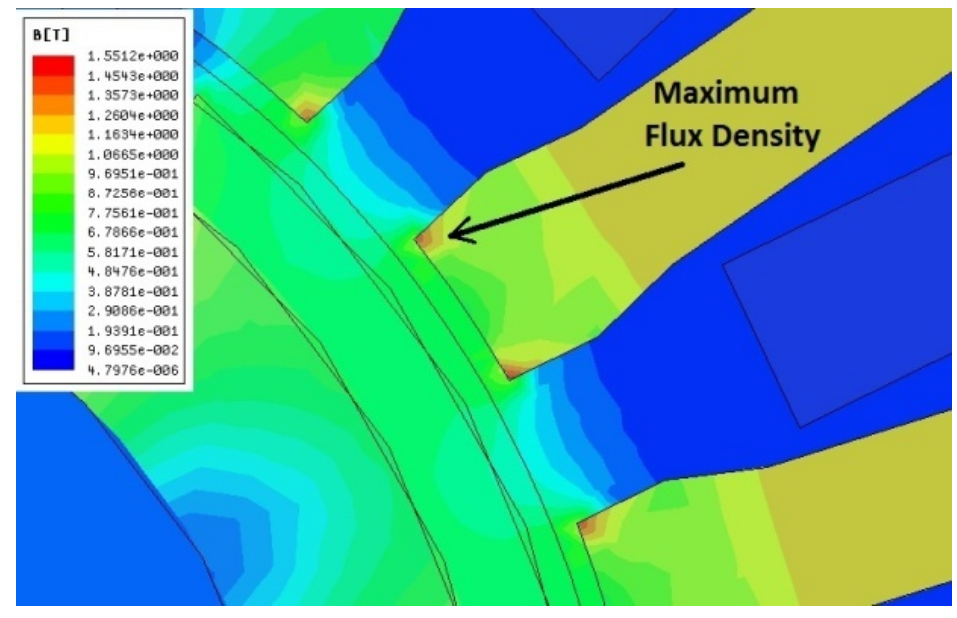

Fig. 9 Flux density distribution. 
Results of flux density in different parts of the motor are listed in table 4. Additionally, they are compared with analytical results. It is obvious that FEA confirms optimized results with agreeable error. Furthermore, flux density in stator yoke, rotor yoke, stator tooth, and air gap are illustrated in Fig. 10, 11, 12 and 13, respectively. These diagrams are plotted in a pole pitch.

Figure 14 shows efficiency versus rotational speed of motor. As shown, efficiency value in motor's rated speed is near to the one calculated by $\mathrm{ABC}$ optimization algorithm.

Table 4: Comparison of the analytical and numerical results.

\begin{tabular}{|l|c|c|c|}
\hline & $\boldsymbol{B}_{\boldsymbol{c s}}$ & $\boldsymbol{B}_{\boldsymbol{c r}}$ & $\boldsymbol{B}_{\boldsymbol{a g}}$ \\
\hline \hline Analytical (T) & 1.5 & 1.5 & 0.55 \\
\hline Numerical (T) & 1.43 & 1.41 & 0.515 \\
\hline \hline Error (\%) & 4.6 & 6 & 6.3 \\
\hline
\end{tabular}

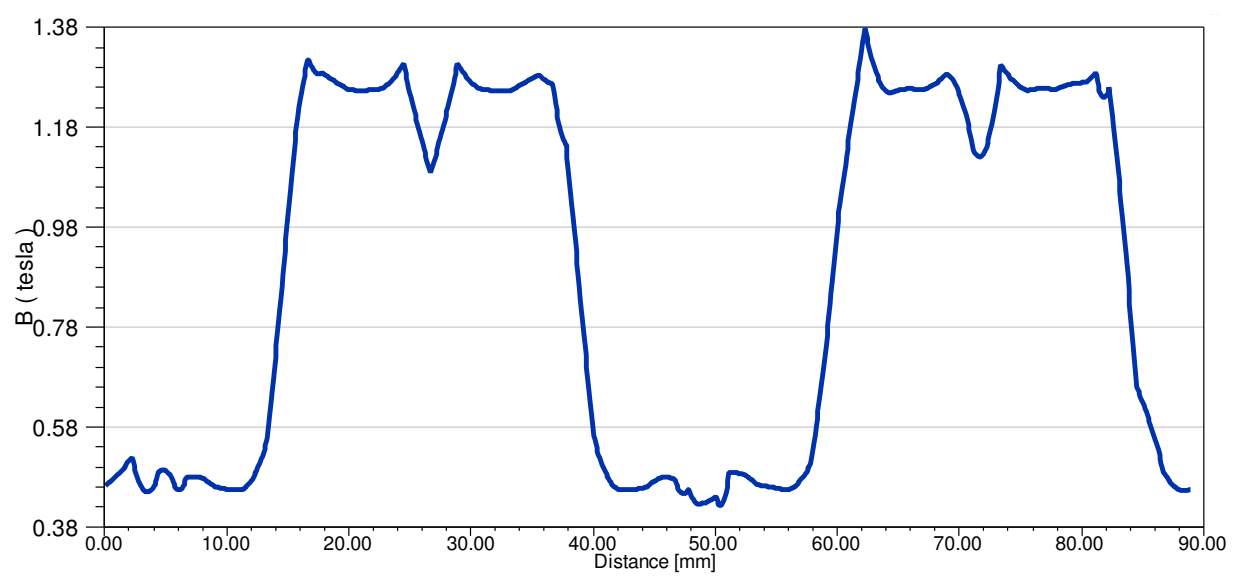

Fig. 10 Flux density in stator yoke.

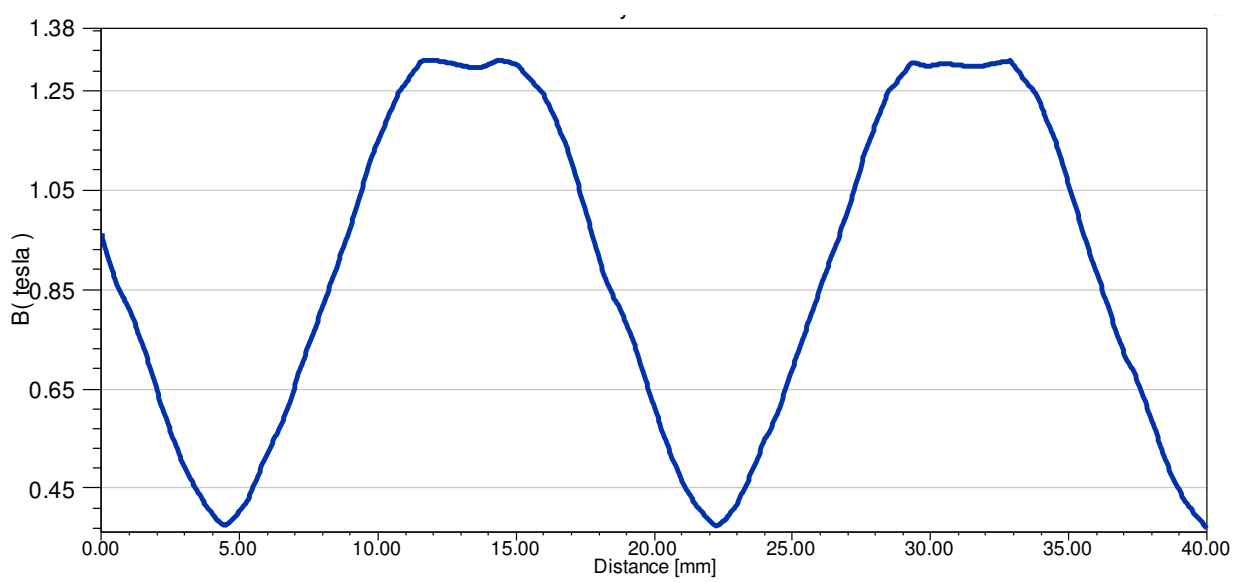

Fig. 11 Flux density in rotor yoke. 


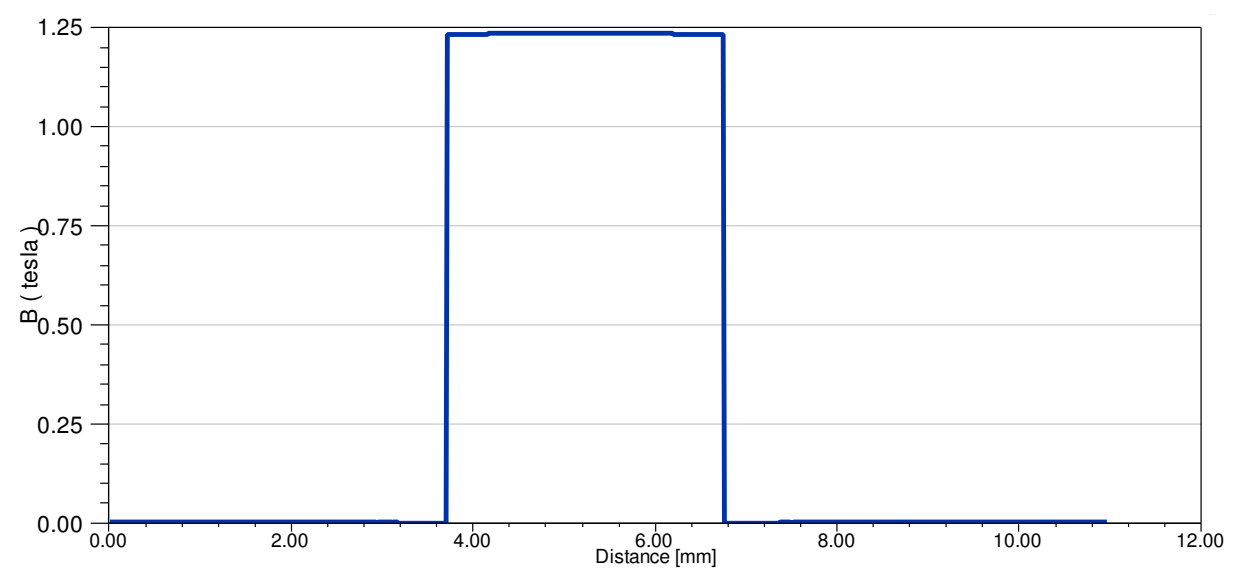

Fig. 12 Flux density in a tooth.

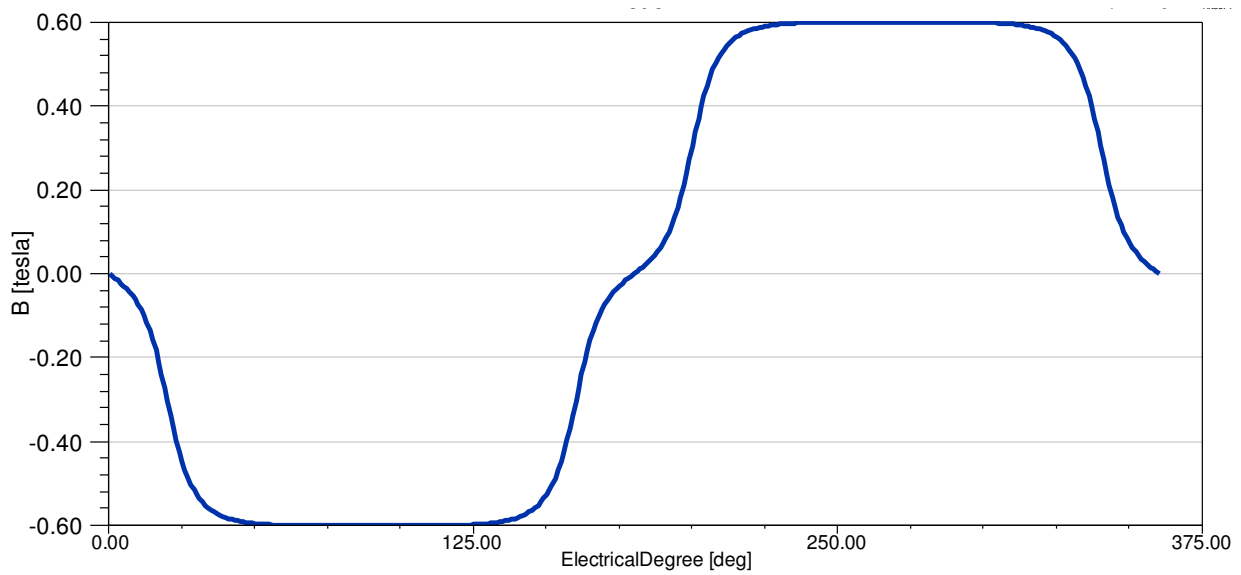

Fig. 13 Flux density of air gap in a pole pitch.

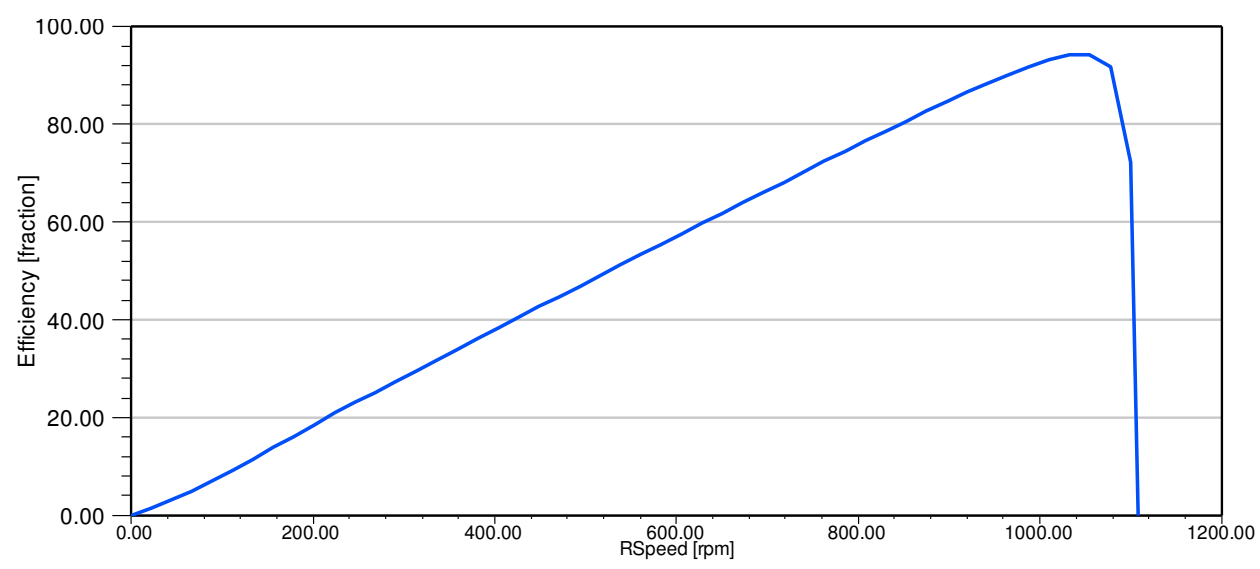

Fig. 14 Efficiency versus rotational speed.

\section{CONCLUSION}

In this paper, Artificial Bee Colony (ABC) algorithm is used for optimum design of a brushless permanent magnet motor. For this propose, three goal functions are maximized: 
efficiency, power density and combination of the two first functions. Then, the optimal design parameters of brushless Permanent Magnet motor are produced. Various tuning of ABC parameters were considered. The best tuning is chosen in terms of goal functions' optimal values, convergence of optimization process, and smoothness of output plot.

Finally, efficiency of this algorithm is validated using a 2-D finite element analysis (Maxwell software). Simulation results confirm optimized data with a little degree of error.

Future work may be devoted to developing other goal functions which result in a more efficient optimization of motor design parameters. Other optimization methods such as bees algorithm, particle swarm optimization, and genetic algorithm can be applied to the considered problem to the hope of achieving more optimal results.

\section{REFERENCES}

[1] Lee, Byoung-Kuk, and Mehrdad Ehsani. Advanced Simulation Model for Brushless DC Motor Drives." Electric Power Components and Systems 31.9 (2003): 841-868.

[2] Yeadon, William H., and Alan W. Yeadon, Handbook of Small Electric Motors. 1 McGrawHill Professional, 2001.

[3] Hendershot, James R., and Timothy John Eastham Miller. Design of Brushless PermanentMagnet Machines. Motor Design Books, 2010.

[4] S.A Gholamian, M. Ardebili, K. Abbaszadeh, "Analytic and FEM Evaluation of Power Density for Various Types of Double-Sided Axial Flux Slotted PM Motors",International Journal of Applied Engineering Research, 3.6 (2008): 749-62.

[5] M. Aydin, S. Huang, T.A Lipo, Optimum design and 3D finite element analysis of nonslotted and slotted internal rotor type axial flux PM disc Machines." Power Engineering Society Summer Meeting, 3. (2001) IEEE, 2001.

[6] S. A. Gholamian, M. Ardebili. K. Abbaszadeh,"Selecting and Construction of High Power Density Double-Sided Axial Flux Slotted Permanent Magnet Motors for Electric Vehicles", International Review Of Electrical Engineering-IREE 4.3 (2009): 477-84.

[7] Radulescu, Mircea M., Claudia Martis, Iqbbal Husain, "Design and Performance of a Small Doubly-Salient Rotor-Permanent-Magnet Motor", Electric Power Components and Systems 30.5 (2002): 823-32.

[8] Upadhyay, Parag R., and K. R. Rajagopal "FE Analysis and Computer-Aided Design of a Sandwiched Axial-Flux Permanent Magnet Brushless DC Motor",. Magnetics, IEEE Transactions on 42.10 (2006): 3401-03.

[9] Von Frisch Karl. "Bees: Their Vision, Chemical Senses and Language.” New York:Cornell University Press, (1976).

[10] Seeley Thomas D. The Wisdom of the Hive: The Social Physiology of Honey Bee Colonies. Massachusetts: Harvard University Press, 1996.

[11] Bonabeau, Eric, Marco Dorigo, and Guy Theraulaz. Swarm Intelligence: "From Natural to Artificial Systems". New York: Oxford University Press, 1999.

[12] Camazine S, Deneubourg J, Franks NR, Sneyd J, Theraula G and Bonabeau E. "Self Organization in Biological Systems". Princeton: Princeton University Press, 2003.

[13] M.V.k. Chari, and P. Silvester, "Finite- Element Analysis of Magnetically Saturated D-C Machines",. Power Apparatus and Systems, IEEE Transactions on 5 (1971): 2362-72.

[14] Sharifian, M. B. B., H. Vahed Kalankesh, and M. R. Feyzi. "Multiobjective Optimization of Induction Motor Slot Design Using Finite Element Method." Electronics, Circuits and Systems, Proceedings of the 2003 10th IEEE International Conference on. 3. IEEE, 2003. 